\title{
Impact of education on food behaviour, body composition and physical fitness in children
}

\author{
Jana Parizkova* \\ Obesity Management Centre, Institute of Endocrinology, Narodni 8, Prague 1, 116 94, Czech Republic
}

The increasing prevalence of obesity during growth and development is significantly related to the education of children, and also to that of parents who influence food intake and physical activity from the beginning of life. The effect of maternal level of education has been shown in regular anthropometric surveys in 10-year intervals since 1951. This concerns the mother's own nutrition and physical activity regimen as well as the child's nutrition since birth, including the duration of breast-feeding. Children of parents with overweight and obesity were shown more often to be obese, as was the case for children from families with the lowest level of education, or from smaller communities where the level of education is usually lower than in larger cities. The composition of the mother's diet during pregnancy had, for example, an effect on the blood lipids of newborns. During preschool age, less body fat, a higher level of HDL, and higher levels of cardiorespiratory fitness, skill and physical performance were found in active children. In school-age children, when obesity increases, a number of prevention programmes using diet, exercise and behavioural intervention have been developed for schools, communities, churches, and/or have been organized by special institutions and medical centres, which were most efficient in family groups. The greatest reduction of weight, BMI and fatness, and improvement of functional capacity, and hormonal and metabolic parameters were achieved in summer camps or spas, with consistent and monitored nutrition, exercise and behavioural treatment. Fluctuation of positive outcomes occurred due to the interruption of the educational process during the school year, and repeated long-lasting interventions have been always necessary for permanent desirable results.

Education: Nutrition: Obesity prevention

Inadequate life habits introduced during the last few decades, which can result in health complications including obesity, concern at present also children and adolescents. The International Obesity Task Force ${ }^{(1)}$ and the $\mathrm{WHO}^{(2)}$ evaluated the global epidemic of obesity also as an essential educational problem. The significant impact of the environment - especially nutrition $^{(2,3)}$ - has been considered during recent years as the most important one, especially influencing subjects with genetic predispositions concerning metabolic characteristics, etc.

During growth, the development of the organism can be best influenced due to its plasticity; the impact of negative environmental stimuli $^{(2-4)}$ concerning lifestyle can be at least partly eliminated in those whose education helps to resist or compensate undesirable influences and who adhere to the principles of rational diet and overall lifestyle. Adequate cognitive growth and social maturation resulting from proper education can contribute to adequate dietary, motor and social habits, which might result - under further positive environmental conditions - in good health, and also in an optimal somatic, functional, psychological and social development, which is the best criterion with regard to the efficiency of educational interventions.

\section{Historical aspects}

The increase in prevalence of overweight and obesity has been shown in most industrially developed countries, but also in other countries where life conditions have changed rapidly during recent years ${ }^{(1,2)}$; this concerns also very young subjects. Comparisons along time, and/or among populations with different degrees of industrial, economic and social development, demonstrate that. For example, the measurement of Czech children started in 1895 by Professor J. Matiegka (5; published in 1927) enabled the comparison of child development since the end of the nineteenth century until recent time. At the end of the nineteenth century, children were not only smaller, but overweight and obesity was obviously much rarer $^{(5)}$.

\section{International comparisons}

In spite of a lower prevalence of overweight and obesity in the Czech Republic as compared with the USA and Europe ${ }^{(1,2)}$, the increasing trend has indicated an urgent need to intervene by all possible means, including proper and innovative education. After initial measurements of Czech children in 1895, regular measurements have continued in 10-year intervals since the half of the last century until present, always in tens of thousands of subjects (each follow-up of about 20-60000 children; 6-11).

The last measurements in 2001 included 18584 younger children from 6 to 10.99 years of age, and 40525 schoolchildren and adolescents ${ }^{(7,11)}$. Average values and percentiles of eleven anthropological parameters were established, and the 
effect of various factors (ascertained by questionnaires, thirtyfive items) such as family situation, education of parents, birth weight, duration of breast-feeding, participation in exercise, etc were evaluated, and their impact was compared in different periods of these studies since 1951 .

Comparison of the changes of BMI centiles since 1951 up to 2001 in Czech children was conducted ${ }^{(6-8,11)}$. Values of BMI at the 10th percentile did not change, values of 50th percentiles changed a little only at certain ages, mostly in boys. BMI at the 90th percentile have shifted during the 50-year period more markedly; in boys along the whole age span, but in girls only up to 14 years of age. This means that the percentage of children with marked degrees of obesity has increased relatively most from 1951 to $2001^{(11)}$. Older adolescent girls have taken greater care about their body size and silhouette, obviously also due to changed diet. The effect of the Western criteria of beauty has had a significant effect also in this respect, which was finally quite a desirable one.

\section{Secular and developmental changes}

Secular changes of growth and development were shown; in addition, the measurements in Czech children could also demonstrate the shift of adiposity rebound (AR) to an earlier age ${ }^{(9-12)}$, which is an especially important finding about recent child growth and development. It is possible to assume that this has occurred also in other child populations. This shift is considered as a marker of an easier and earlier development of enhanced fatness, and increased BMI during following development (Tables $1 \mathrm{a}, \mathrm{b} ; 12$ ). This results obviously from the changes in lifestyle since the earliest periods of life - nutrition and reduced physical activity of the family, which is significantly influenced by the level of education of parents.

Compared with 1951, the time of AR has gradually shifted to earlier ages. Among boys at the 50th percentile for BMIfor-age, AR occured at the age of 4.9 compared with 6.2 years in 1951. AR among girls at the 50th percentile occured 1.2 years earlier. $\mathrm{AR}$ at the 10th and 50th percentiles occured later among girls compared with boys in 1951 as well as in 2001. In contrast, girls at the 90th percentile experienced AR earlier than boys at the same percentile (Tables 1a, b; 12). Similar long-term studies since the end of the nineteenth century have not been conducted in children of other countries.

The prevalence of subjects characterized by higher and/or lower BMI centiles changes markedly according to age - adolescents older than about 15 years at the occasion of the last measurement in 2001 generally had a lower prevalence of overweight and obesity ${ }^{(8,11,12)}$. Development and growth

Table 1a. Age (years) of adiposity rebound in 1951 and 2001 in boys $^{(12)}$

\begin{tabular}{lccc}
\hline & \multicolumn{3}{c}{ Percentile } \\
\cline { 2 - 4 } Year of the survey & 10 th & 50 th & 90 th \\
\hline 1951 & $6 \cdot 4$ & $6 \cdot 2$ & $6 \cdot 0$ \\
2001 & $5 \cdot 3$ & 4.9 & $4 \cdot 2$ \\
Difference & $1 \cdot 1$ & $1 \cdot 3$ & $1 \cdot 8$ \\
\hline
\end{tabular}

Table 1b. Age (years) of adiposity rebound in 1991 and 2001 in girls ${ }^{(12)}$

\begin{tabular}{lccc}
\hline & \multicolumn{3}{c}{ Percentile } \\
\cline { 2 - 4 } Year of the survey & 10 th & 50 th & 90 th \\
\hline 1951 & 6.5 & 6.4 & 5.8 \\
2001 & $5 \cdot 6$ & $5 \cdot 2$ & 4.1 \\
Difference & 0.9 & 1.2 & $1 \cdot 7$
\end{tabular}

under conditions of communities with different numbers of inhabitants also had an impact on the prevalence of BMI in different centiles: higher BMI was more frequent in children from smaller communities ${ }^{(7,10,11)}$. This finding could also be related to the effect of education in families, which has been always found to be on a higher level in greater cities. The effect of genetic and hereditary factors was also shown by a higher ratio of children with higher values of BMI who had parents characterized by higher $\mathrm{BMI}^{(7,11)}$.

\section{Effect of mother's nutrition and birth weight}

Another study in Italian mothers and children showed a significant effect of the composition of the mother's nutrition during pregnancy on the metabolic characteristics of newborns. The amount of proteins and carbohydrates in the mother's diet during various trimesters of pregnancy had a significant relationship with the level of, for example, serum lipids (total cholesterol, HDL-cholesterol) in their offspring (Table 2). However, when we analysed the effect of mother's nutrition with regard to gender, it was shown that this effect was significant only in boys ${ }^{(13,14)}$. As considered more recently, obesity can have its origins during pregnancy already in the womb. Pregnant women are now advised to cut out certain foodstuffs - for example, junk food, for their children's sake ${ }^{(1)}$.

Increased birth weight of children of healthy mothers indicates, inter alia, higher dietary intake during pregnancy. Children born heavier were characterized by greater proportion of individuals with higher BMI also at the age of 6-10.99 years

Table 2. The relationships between the composition of the mother's diet in different trimesters of pregnancy, and level of serum lipids in newborns $^{(14)}$

\begin{tabular}{|c|c|c|c|c|c|}
\hline \multirow[b]{3}{*}{ Mother's diet } & \multirow[b]{3}{*}{ Trimester } & \multicolumn{4}{|c|}{ Newborns } \\
\hline & & \multicolumn{2}{|c|}{ Both genders } & \multicolumn{2}{|c|}{ Boys } \\
\hline & & $r$ & $p$ & $r$ & $p$ \\
\hline Protein $(\mathrm{g} / \mathrm{d})$ & $1 \mathrm{st}$ & & & $\begin{array}{c}\text { HDL } \\
-0.544\end{array}$ & 0.04 \\
\hline \multirow[t]{5}{*}{ Carbohydrate $(\mathrm{g} / \mathrm{d})$} & $1 \mathrm{st}$ & $\begin{array}{c}\text { TCh } \\
-0.466\end{array}$ & 0.03 & TCh & \\
\hline & $\begin{array}{l}\text { 2nd } \\
\text { 2nd }\end{array}$ & $\begin{array}{c}-0.597 \\
\text { HDL }\end{array}$ & 0.004 & $\begin{array}{c}-0.654 \\
\text { HDL }\end{array}$ & 0.01 \\
\hline & 3rd & $\begin{array}{c}-0.536 \\
\text { TCh }\end{array}$ & 0.01 & -0.635 & 0.01 \\
\hline & & $\begin{array}{c}-0.436 \\
\text { HDL }\end{array}$ & 0.04 & HDL & \\
\hline & & -0.439 & 0.04 & -0.579 & 0.01 \\
\hline
\end{tabular}

TCh, total cholesterol. 
( $n$ 18584; 7,11). Similar results were gained in another study when following preschool children $(n$ 9092; 13). Those who were born heavier also had at the age of 6-7 years higher body weight and BMI, and were characterized also by higher values of other bodily dimensions, for example, circumferential measures (greater chest and hip circumference), and higher level of motor performance in selected motor tasks. Children born heavier were more skillful, for example, had better results in the test of ball throwing by the left hand ${ }^{(13)}$.

Duration of breast-feeding has been shown to be a significant factor relating to body size during later growth. Studies of Czech children showed a higher percentage of children characterized by higher BMI which were not breastfed, as compared with children who were breastfed up to more than 6 months of age $^{(11)}$. As found in the group of children born in 1995-2000 ( $n$ 9602), duration of breast-feeding was longest in mothers with the highest level of education (university; 13). Education and instruction of mothers with regard to their diet during pregnancy and duration of breast-feeding have gained great attention in recent decades in not only in the Czech Republic ${ }^{(13,15)}$, but also in all other countries, and mostly a positive effect of breast-feeding was demonstrated in a number of studies with regard to obesity prevention, and also to other health risks, psychological and emotional development, etc ${ }^{(1)}$.

\section{Effect of family education}

Educational level in the family, i.e. education level of the father and of the mother, has also shown a positive impact - the percentage of children with the highest BMI at the age of 6 to 10.99 years of age was highest in families where both parents had a lowest degree of education ${ }^{(11)}$. Similar results were also found in another study of preschool children mentioned above ( $n$ 9587), in which parents were divided into four categories according to educational level (1, basic level; 2, skilled manual worker; 3 , high school with higher school certificate; 4, university education). This study also showed better results, i.e. the lowest prevalence of obesity (BMI above 90th centile), in children from families with a father with the highest level of education (level 4) and a mother with a middle degree of education (level 3) ${ }^{(13)}$. Apparently, higher parental education influences significantly the regimen of life in the family including nutrition and also the physical activity regimen, preventing overweight and obesity of children.

Education of the mother also has an effect on the selection and number of refused foods for their children of preschool age ${ }^{(16)}$. More educated and knowledgeable mothers selected with greater care foodstuffs for their children, which were not suitable for optimal development. The role of mothers was always mostly important, for example, familial patterns of overweight were found to be mediated by mother's dietary disinhibition $^{(17)}$. Family lifestyle, parental BMI and parental eating attitudes were shown, for example, by a longitudinal study to be a predictor of children's BMI ${ }^{(18)}$. This concerns also television viewing, physical activity and snacking, which influence negatively the BMI of children ${ }^{(1,2,19,20)}$.

Too-large weight increments in children during the initial weeks and months of their life - considered formerly as positive - are at present evaluated as a marker of easier development of obesity during later development. Previous energy recommendations $\left(\mathrm{WHO}^{(1,2)}\right)$ are at present considered too high, as an adequate somatic development can be assured with about 10-15\% lower energy intake. Babies are thus often overfed due to outdated growth charts and RDAs. Therefore, present RDAs for children have been reduced. This issue was discussed also in special meetings and congresses concerning this problem (for example, at the occasion of the recent International Congresses of Nutrition (IUNS) in Montreal in 1999, in Durban (2005), or, for example, in the congress on 'Fetal origins of adult diseases' (Mumbai 2001) where a special session on obesity was also included. The WHO has also focused attention on this particular problem ${ }^{(2)}$.

\section{Effect of energy output and physical activity}

The mentioned problems have been discussed under conditions when basic RDAs are met, as usual in developed countries. But all recommendations must also be considered in relation to overall energy needs, i.e. also related to the energy output, influenced mainly by physical activity level ${ }^{(13)}$. Studies in preschool children have given basic data on somatic and motor development from 3 to 6 years ${ }^{(13,19)}$. Comparison of preschool children (mean age 4.7 years) differing in the level of spontaneous physical activity showed that more active children achieved slightly lower values of BMI and of fat percentage, along with slightly higher energy intakes and higher levels of cardiorespiratory fitness (as evaluated by the results of a modified step test for preschool children; 13,19). HDL level was significantly higher, which indicates that their metabolic development was more positive. Percentage of body fat correlated positively with total cholesterol and TAG level ${ }^{(19)}$ which showed that increased fat deposition has an undesirable effect already in children of 4.7 years of age.

Therefore, when evaluating energy intake, food choice and habits, it is necessary to relate them also to energy output, as a higher dietary intake has a different impact in children with higher and/or lower levels of physical activity and motor performance.

Similarly, as with regard to nutrition, also activity and exercise habits can be established due to various family conditions and level of education at an early age, which are dependent not only on genetic factors (as shown by motor studies in mono- and dizygotic twins - see 13), but also, in this respect, on family habits and educational practices. As shown by psychologists in humans, not only nutrition habits, but also motor habits and physical activity level can be ingrained by education as early as $2-3$ years of age ${ }^{(13,19)}$, and can result also in delayed consequences concerning health and overall metabolic and physical fitness in later years of life. This was, however, proved mainly in laboratory models with experimental animals ${ }^{(13)}$ where the long-term follow-up is possible. However, any child can learn and be educated to eat properly, or the reverse. Moreover, a child can learn to move, or learn not to move, and to prefer to be sedentary.

Not only somatic, but also motor development and level of physical performance were shown to be influenced by regular exercise $^{(13,19)}$, as shown in children participating in specially organized physical education for young preschool children together with their mothers (and/or fathers, or any other caretaker ${ }^{(13,19)}$. This form of physical education was introduced in the Czech Republic during the 1960s on a mass scale, and has been continuing until the present time. Early intervention 
during preschool age is desirable, as the level of physical activity is spontaneously high ${ }^{(13,19,21)}$. After entering the primary school the motor activity of children decreases both spontaneously (as shown by a longitudinal study; 13) and due to the change in lifestyle.

\section{Combined educational approach during school age}

During school age and pre-adolescence, overweight and obesity increase more often. A combined approach including monitored diet, exercise and behaviour is again most often used, and differentiated - in an optimal case - according to age, degree of sexual maturation, gender, duration and degree of overweight and/or obesity ${ }^{(22-24)}$. The mentioned factors are used both for the prevention and treatment of obesity. The best situation in this respect had special out-patient courses, which were organized both for parents and children.

As shown by further studies, in well-organized groups with long-lasting nutrition education and control of somatic changes, very good results were achieved. Short- and longterm effects were beneficial when such a combined approach using dietary-behavioural-physical activity intervention were followed up ${ }^{(23)}$. A favourable effect of a structured out-patient programme using the same items in a group of obese children - OBELDICKS - was found ${ }^{(24,25)}$.

Clinical counselling and education had better results in family-based group treatment of obesity as compared with individual treatment. Children who participated in group treatment lost more weight for height $(6.8 \%)$ than children receiving routine counselling $(1.8 \%)$. After 6 months after this intervention, positive results were partly lost, but for changes in weight, height and BMI, the differences were always significantly better when group counselling was used ${ }^{(26)}$. In-patient treatment along with nutrition education was also introduced in special clinics, but this concerned especially severely obese children who had additional health problems ${ }^{(27)}$.

More recently introduced multidisciplinary programmes of a combined educational dietary-behavioural-physical activity intervention resulted not only in the reduction of BMI and lowering of excess fatness, but also reduction of serum lipids, improved fitness and in improvement of nutritional and physical activity habits. Education and instruction were well organized, and the follow-up was continued during 1 and 2 years ${ }^{(24,25)}$. Various similar out-patient educational programmes and interventions were also conducted, for example, in Finland, Germany, Spain, Czech Republic, Netherlands, Poland and also in the USA, Chile and Israel, all with good results.

As a basis of such programmes, communities ${ }^{(28)}$ and churches were also used. All interventions, including diet and exercise, were arranged both in the framework of school hours, and also as an after-school programme ${ }^{(29,30)}$. Reduction of television viewing as a marker of reduced physical activity is also the part of some programmes.

Special programmes also included education aimed at increasing the consumption of vegetables and fruit. Promotion of milk and milk product consumption was focused in other programmes and educational interventions as a mean for obesity prevention and improved skeletal development (for example, USA, Poland, Sweden, Italy, Greece, etc). Positive results of such educational programmes and interventions conducted in Sweden, Belgium, Spain, Australia, UK, France,
Finland and others were reported (for example, 31-36), and were also presented in a number of lectures and posters, especially in sessions on public health and prevention of the last European Congress on Obesity (ECO) in Budapest in April 2007.

A special problem has always been the drop-out from such intervention programmes, when children and adolescents interrupted their participation and for various reasons did not continue. Often the programmes were not attractive, and the educational part not efficient enough. This occurred mainly when there existed interfering influences from the environment, family, etc during the normal school year and at home. Such conditions could make the application of intervention programme difficult and complicated. Lack of fast positive results also discouraged some children. But those subjects who continued in this sort of programmes and interventions had positive results which mostly outlasted the period of the mentioned studies $^{(34-37)}$. Drop-out has always had serious consequences, as those who did not continue most deteriorated further their somatic, functional, metabolic status, etc and increased more excess fatness, along with further health problems not only at present, but also in future life.

\section{Educational and treatment effect of summer camps}

Of especial importance, summer camps have been organized, both under natural conditions or in a spa, mostly for children and adolescents who were more obese ${ }^{(38-40)}$. Such camps have been organized since the 1950s, for example, in the Czech Republic (former Czechoslovakia), later also in the $\mathrm{UK}^{(41,42)}$, and other countries.

Their purpose can be best achieved, but their organization is costly. The educational practices from all points of view can be optimally arranged, and their impact best controlled, especially from the point of view of fat reduction. This also included the preparation of optimal meals (with monitored energy intake and exclusion of inadequate foodstuffs) and an overall dietary regimen during the day time, along with an adequate and suitable exercise and physical activity regimen.

Behavioural interventions were also included in programmes of such summer or spa interventions, and psychological treatment was essential; all children were comparable in their problems, which enabled more efficient education and treatment. Thus, children felt relaxed and without inhibitions, especially when considering, for example, organized exercises and sports of all suitable character (swimming, games, running, trekking, dancing, etc). The reduction regimen was thus accepted spontaneously and with greater willingness, and was significantly supported by positive results, which were regularly checked ${ }^{(38-42)}$.

There was always a significant reduction of body weight, BMI, and total and subcutaneous fat (Fig. 1). The distribution of subcutaneous fat also changed, i.e. it decreased more markedly on the trunk than on the extremities, and the indices of fat distribution also became closer to the values of normal-weight children of the same age ${ }^{(38)}$. Heart rate increased less during the same standard workload on a veloergometer, and the same was found for oxygen uptake ${ }^{(39,40)}$, i.e. the energy cost of the same workload on a treadmill decreased significantly after excess fat loss. This was found even when the effect of weight bearing during a workload was excluded on a bicycle ergometer ${ }^{(40)}$. 


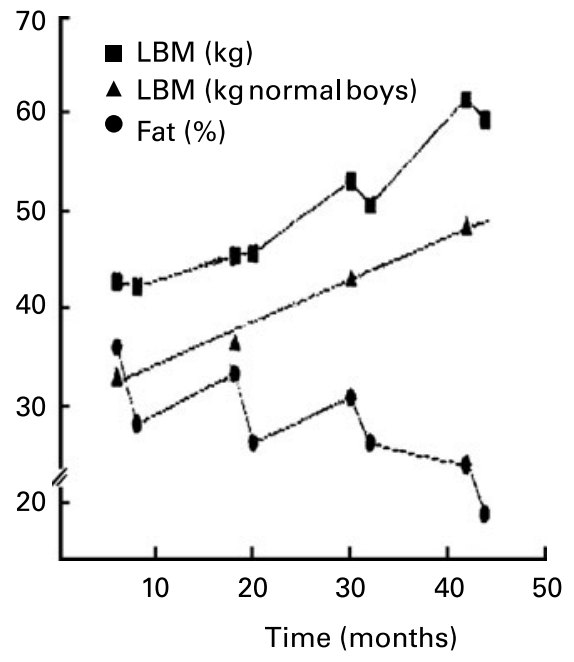

Fig. 1. Changes of body composition - lean, fat-free body mass $(\mathrm{kg})$ in obese boys (- - ) as compared with the development of lean body mass $(\mathrm{kg})$ in normal-weight boys (followed each year at the same age ${ }^{(46)}$ ), and of body fat (\%) $(-)$. Four-year longitudinal study when boys were repeatedly measured each year by densitometry, always before and after four summer camps with reduction treatment (monitored dietary intake, controlled exercise, behavioural intervention and education), from 11 to 14 years (eight measurement 39).

Along with weight, fat, leptin, serum lipid levels and blood pressure decreased significantly ${ }^{(40,43,44)}$. Also blood levels of selected hormones changed significantly along with weight and fat reduction, i.e. insulin, cortisol, thyroxine, etc ${ }^{(45)}$.

Regular control of body weight, BMI, fatness, performance in various sport disciplines and their positive results encouraged children to adhere to the programme and continue until the end of such summer camps. Moreover, children felt happier, relaxed and without inhibitions, and remembered such treatment with pleasure during the whole school year. The psychological effect of the stay in summer camps in groups of children with similar problems and with the same educational intervention was especially positive, and resulted in the best effects during a relatively short time period, as compared with all other treatments. Similar results were also found during spa treatment of the obese ${ }^{(12,43)}$.

\section{Fluctuation of weight, fat and physical fitness after interruption of treatment}

However, during the school year the results of such interventions usually partly disappeared, and further increase of weight and BMI and fatness were observed ${ }^{(38-40)}$. But when it was possible to continue with the mentioned education and intervention during the year (for example, when following children regularly in out-patient departments in paediatric clinics, or in other special centres), and also to repeat such a treatment in summer camps during following years, the final results meant a significant improvement of somatic, functional, biochemical and other parameters even after more years (Fig. 1; 40). This concerned also health status - not only the present, but also future status - as shown particularly by cases of especially motivated subjects.

In regularly exercising boys in sport schools or clubs (more than $6 \mathrm{~h}$ per week of regular training in light athletics and basketball during 8 years) there was a significant effect on body fat development as compared with boys who only had physical education at school (which was the same for both groups) and only irregular exercise (less than $2 \mathrm{~h}$ per week ${ }^{(46)}$ ).

\section{Perspectives and conclusions}

As commented before, the best management of obesity is not to let it develop at all, using proper education and intervention. This was proved especially in those who were committed and educated from the very beginning of life $\mathrm{f}^{(13,19)}$.

However, measures for preventing obesity were known already in the ancient cultures of the Egyptian, Chinese, Indian, Roman and Arabic Empires, etc. The founder of pedagogy - 'teacher of nations' according to UNESCO - John Amos Comenius elaborated the whole education system in greater detail already in the 17 th century ${ }^{(47)}$. His recommendations for education concerning both nutrition and physical activity of children are appropriate even today, and should be implemented with greater effort even under present conditions.

Early beginning of nutritional education and intervention, and adhering to such programmes are recommended as one of the most efficient means for positive health not only during growth, but during the whole life. This is started by the nutritional status of the mother, adequate nutrition during pregnancy, breast-feeding period and proper nutritional and educational management of the child from birth, and of course later on. Repeating all these old wisdoms is still justified: the deterioration of the overall situation, i.e. the global epidemic of obesity which concerns at present also children and adolescents, means an urgent health problem for the whole lifespan. But changing life conditions requires new innovative programmes of intervention, starting with an adequate education which until now has not been shown as effective enough.

\section{Activities of intergovernmental organizations}

The WHO has paid attention to this problem, and not only to obesity which has already started, but also to educational interventions not only in families, but also schools which should prevent it. This should contribute to health development, and includes, as for example, 'Nutrition-Friendly School initiative NFS1', both diet and increased physical activity and exercise (WHO - 'move for health' ...health and development through physical activity and sport'; 48). A document on 'Nutritional education in primary schools: a planning guide for curriculum development: Promoting lifelong healthy eating habits' was produced by the FAO in 2005 (Rome) ${ }^{(49 a, b)}$. Other documents of the WHO and FAO are available during recent years, and can also contribute to the prevention of health risks resulting from obesity.

\section{Conflict of interest statement.}

The author has no conflicts of interest to report

\section{References}

1. International Obesity Taskforce: Childhood obesity. http://www. iotf.org

2. WHO (1998) Obesity: Prevention and Managing the Global Epidemic, WHO Consultation on Obesity, 3-5 June 1997. Geneva, Switzerland: WHO. 
3. Bellisle F (2004) Effects of diet on behaviour and cognition in children. Br J Nutr 92, Suppl. 2, S227-S232.

4. Bellisle F \& Drewnowski A (2007) Intense sweeteners, energy intake and the control of body weight. Eur J Clin Nutr 61, 691-700.

5. Matiegka J (1927) Somatology of children. Czech Acad Sci Arts $(C A V U)$ Prague (in Czech).

6. Blaha P, Vignerova J, Kobzova J, Krejcovsky L \& Riedlova J (2003) State anthropological research of children and youth 2001. Ces-slov Pediatr 58, 766-770 (in Czech).

7. Blaha P, Vignerova J, Riedlova J, Kobzova J, Krejcovsky L \& Brabec M (2005) The 6th Nation-wide Czech anthropological survey of children and adolescents 2001 Czech Republic. Basic body parameters $0-19$ years, percentile charts $0-18$ years etc. Prague (in Czech): State Health Institute.

8. Vignerova J, Lhotska L, Blaha P \& Roth Z (1997) Growth of the Czech child population 0-18 years compared with the World Health Organization growth reference. Am J Hum Biol 9, 459-468.

9. Vignerova J, Lhotska L \& Blaha P (2001) Proposed standard definition for child overweight and obesity. Cent Eur J Public Health 9, 145-146.

10. Vignerova J, Brabec M \& Blaha P (2006) Two centuries of growth among Czech children and youth. Econ Hum Biol 4, 237-252.

11. Vignerova J, Riedlova J, Blaha P, Kobzova J, Krejcovsky L, Brabec M \& Hruskova M (2006) 6th Nation-wide anthropological survey of children and adolescents 2001 Czech Republic Summary results. Prague (in Czech): Faculty of Natural Sciences, Charles University and State Health Institute.

12. Vignerova J, Humenikova L, Brabec M, Riedlova J \& Blaha P (2007) Long-term changes in body weight, BMI and adiposity rebound among children and adolescents in the Czech Republic. Econ Hum Biol 5, 409-425.

13. Parizkova J (1996) Nutrition, Physical Activity and Health in Early Life, 1st ed. Boca Raton, New York, London and Tokyo: CRC Press.

14. Alberti-Fidanza A, Parizkova J \& Fruttini D (1995) Relationships between mother's and newborn's nutritional and blood lipids variables. Eur J Clin Nutr 49, 289-298.

15. Toschke M, Vignerova J, Lhotska L, Osancova K, Koletzko B \& Kries R (2002) Overweight and obesity in 6-14-year-old Czech children in 1991. Protective effect of breast-feeding. J Pediatr 141, 764-769.

16. Frankova S, Odehnal J \& Parizkova J (2000) Nutrition and personality development of children. HZ Edition, Prague (in Czech).

17. Cutting TM, Fisher JO, Grimm-Thoma K \& Birch LL (1999) Like mother, like daughter: family patterns of overweight are mediated by mother's dietary disinhibition. Am J Clin Nutr 69, 608-613.

18. Burke V, Bellini LJ \& Dunbar D (2001) Family lifestyle and parental body mass index as predictors of body mass index in Australian children: a longitudinal study. Int J Obes Relat Metab Disord 25, 147-157.

19. Parizkova J (1998) Interaction between physical activity and nutrition early in life and their impact on later development. Nutr Res Rev 11, 1-21.

20. Bellisle F (2003) Why should we study human food intake behavior? Nutr Metab Cardiovasc Dis 13, 189-193.

21. Moore LL, Nguyen UDT, Rothman KJ, Cupples LA \& CurtisEllison R (1995) Preschool physical activity level and change in body fatness in young children: The Framingham children's study. Am J Epidemiol 142, 982-988.

22. Bellisle F (1999) Food choice, appetite and physical activity. Public Health Nutr 2 (3A), 357-361.
23. Nemet D, Barkan S, Epstein $Y$, Friedland O, Kowen $G$ \& Eliakim A (2005) Short- and long-term beneficial effects of combined dietary-behavioral-physical activity intervention for the treatment of childhood obesity. Pediatrics 115, $442-449$.

24. Reinehr T, Kersting M, Wollenhaupt A, Alexy U, Kling B, Strobele K \& Andler W (2005) Evaluation of the training program 'OBELDICKS' for obese children and adolescents. Klin Pediatr 217, 1-8 (in German).

25. Reinehr T, de Souza G, Toschke AM \& Andler W (2006) Long-term follow-up of cardiovascular disease risk factors in children after an obesity intervention. Am J Clin Nutr 84, 490-496.

26. Kalavainen MP, Korppi MO \& Nuutinen OM (2007) Clinical efficacy of group-based treatment for childhood obesity compared to routinely given individual counselling Int $J$ Obes (Lond) Apr 17 (Epub ahead of print).

27. Fennig S \& Fennig S (2006) Can we treat morbid obese children in a behavioral inpatient program? Pediatr Endocrinol Rev 3 , Suppl. 4, 590-596.

28. Gillis D, Brauner M \& Granot E (2007) A community-based behavior modification intervention for childhood obesity. J Pediatr Endocrinol Metab 20, 197-203.

29. Sharma M (2006) School-based intervention for childhood and adolescent obesity. Obes Rev 7, 261-269.

30. Zahner L, Puder JJ, Roth R, Schmid M, Guldimann R, Puhse U, Knopfli M, Braun-Fahrlander C, Marti B \& Kriemler S (2006) A school-based physical activity program to improve health and fitness in children aged 6-13 years ('Kinder-Sportstudie KISS'): study design of a randomized controlled trial. (ISRCTN15360785). BMC Public Health 6, 147.

31. Carrel AL, Clark RR, Peterson SF, Nemeth BA, Sullivan J \& Allen DB (2005) Improvement of fitness, body composition, and insulin sensitivity in overweight children in a schoolbased program: a randomized, controlled study. Arch Pediatr Adolesc Med 159, 963-968.

32. Campbell K, Waters E, O'Meara S \& Summerbell C (2001) Intervention for preventing obesity in childhood. A systematic review. Obes Rev 2, 149-157.

33. Summerbell CD, Waters E, Edmunds LD, Kelly S, Brown T \& Campbell KJ (2005) Interventions for preventing obesity in children. Cochrane Database Syst Rev 3, CD001871.

34. Whitlock EP, Williams SB, Gold R, Smith PR \& Shipman SA (2005) Screening and interventions for childhood overweight: a summary of evidence for the US Preventive services Task Force. Pediatrics 116, 125-144.

35. Collins CE, Warren J, Neve M, McCoy P \& Stokes BJ (2006) Measuring effectiveness of dietetic interventions in child obesity: a systematic review of randomized trials. Arch Pediatr Adolesc Med 160, 906-922.

36. Carrel A, Meinen A, Garry C \& Storandt R (2005) Effect of nutrition education and exercise in obese children: the HoChunk youth fitness program. WMJ 104, 44-47.

37. Korsten-Reck U, Kromeyer-Hauschild K, Wolfarth B, Dickhuth HH \& Berg A (2005) Freiburg intervention trial for obese children (FITOC): results of a clinical observation study. Int $J$ Obes (Lond) 29, 356-361.

38. Parizkova J (1993) Obesity and its treatment by diet and exercise. In Nutrition and Fitness in Health and Disease, vol. 72, pp. 78-91 [A Simopoulos, editor]. World Rev Nutr Diet. Basel: Karger.

39. Parizkova J (1998) Treatment and prevention of obesity by exercise in Czech children. In Physical Fitness and Nutrition During Growth. Studies in Children and Youth in Different Environments, 1st ed., pp. 145-154 [J Parizkova and AP Hills, editors]. Basel: Karger. 
40. Parizkova J \& Hills AP (2005) Childhood Obesity: Prevention and Treatment. Boca Raton, London, New York and Washington, DC: CRC Press, 2nd edn.

41. Gately PJ, Cooke CB, Butterly RJ, Mackreth P \& Carroll S (2000) The effects of a children's summer camp programme on weight loss, with a 10 month follow-up. Int J Obes Relat Metab Disord 24, 1445-1452.

42. Gately PJ, Cooke CB, Barth JH, Bewick BM, Radley D \& Hill AJ (2005) Children's residential weight-loss program can work: a prospective cohort study of short-term outcomes for overweight and obese children. Pediatrics 116, 73-77.

43. Liskova S, Hosek P \& Stozicky F (1998) The metabolic syndrome and cardiovascular risk factors in obese children. Int $J$ Obes Relat Metab Disord 22, S25.

44. Kratzsch J, Dehmel B, Pulzer F, Keller E, Englaro P, Blum WF \& Wabitsch M (1997) Increased serum GHBP values in obese pubertal children and adolescents: relationship to body composition, leptin and indicators of metabolic disturbances. Int $J$ Obes Relat Metab Disord 21, 1130-1136.
45. Sonka J, Kostiuk P, Hilgertova J, Limanova Y \& Drozdova V (1993) Hormonal and metabolic adaptation to a reducing regimen in children. Acta Univ Carol 39, 33-38.

46. Parizkova J (1977) Body Fat and Physical Fitness. Body Composition and Lipid Metabolism in Different Regimes of Physical Activity, pp. 133-139. The Hague: Martinus Nijhoff B.V./Medical Division.

47. Comenius-Komensky JA (1632) Schola Infantiae - School of Infancy. An Essay on the Education of Youth During Their First Six Years, Boston, New York and Chicago: Heath's Pedagogical Library -27. Heath DC \& Comp. Publ., (English version 1898) .

48. Organization Mondiale de la Sante (2003) Initiative Mondiale Annuelle 'Pour votre Sante, bougez'. Document analytique. WHO/NMH/PAH/03.1. Geneva: WHO.

49. Food and Agricultural Organization (2005) a. Promoting Lifelong Healthy Eating Habits, in Children. FAO, Rome. b. Naturalpath datacom., You Tube - Instilling Lifelong Health Habits in Children. Naturalpath.com.wwwyoutube.com/watch?v = IB9CvUvx8tY. 